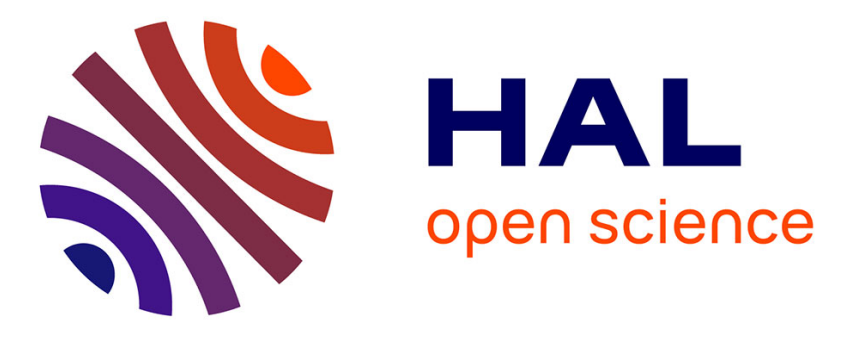

\title{
LES of longitudinal and transverse self-excited combustion instabilities in a bluff-body stabilized turbulent premixed flame
}

Abdulla Ghani, Thierry Poinsot, Laurent Gicquel, Gabriel Staffelbach

\section{To cite this version:}

Abdulla Ghani, Thierry Poinsot, Laurent Gicquel, Gabriel Staffelbach. LES of longitudinal and transverse self-excited combustion instabilities in a bluff-body stabilized turbulent premixed flame. Combustion and Flame, 2015, vol.162 ( $\mathrm{n}^{\circ}$ 11), pp. 4075-4083. 10.1016/j.combustflame.2015.08.024 . hal-01235018

\author{
HAL Id: hal-01235018 \\ https://hal.science/hal-01235018
}

Submitted on 27 Nov 2015

HAL is a multi-disciplinary open access archive for the deposit and dissemination of scientific research documents, whether they are published or not. The documents may come from teaching and research institutions in France or abroad, or from public or private research centers.
L'archive ouverte pluridisciplinaire HAL, est destinée au dépôt et à la diffusion de documents scientifiques de niveau recherche, publiés ou non, émanant des établissements d'enseignement et de recherche français ou étrangers, des laboratoires publics ou privés. 


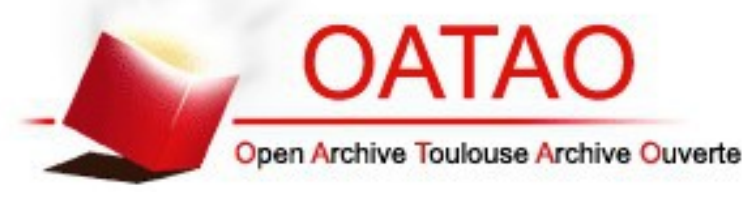

\section{Open Archive TOULOUSE Archive Ouverte (OATAO)}

OATAO is an open access repository that collects the work of Toulouse researchers and makes it freely available over the web where possible.

This is an author-deposited version published in : http://oatao.univ-toulouse.fr/ Eprints ID : 14487

To link to this article : DOI:10.1016/j.combustflame.2015.08.024 URL : http://dx.doi.org/10.1016/j.combustflame.2015.08.024

To cite this version : Ghani, Abdulla and Poinsot, Thierry and Gicquel, Laurent and Staffelbach, Gabriel LES of longitudinal and transverse self-excited combustion instabilities in a bluff-body stabilized turbulent premixed flame. (2015) Combustion and Flame, vol.162 ( $\left.{ }^{\circ} 11\right)$. pp. 4075-4083. ISSN 00102180

Any correspondance concerning this service should be sent to the repository administrator: staff-oatao@listes-diff.inp-toulouse.fr 


\title{
LES of longitudinal and transverse self-excited combustion instabilities in a bluff-body stabilized turbulent premixed flame
}

\author{
Abdulla Ghani ${ }^{\mathrm{a}, *}$, Thierry Poinsot ${ }^{\mathrm{b}}$, Laurent Gicquel ${ }^{\mathrm{a}}$, Gabriel Staffelbach ${ }^{\mathrm{a}}$ \\ ${ }^{a}$ CERFACS, 42 Avenue Gaspard Coriolis, 31057 Toulouse, Cedex 01, France \\ b CNRS-IMFT, 1 Allée du Professeur Camille Soula, Toulouse 31400, Cedex, France
}

\begin{abstract}
A B S T R A C T
Combustion dynamics of a V-flame in an afterburner-type configuration are investigated using high-order compressible large eddy simulations (LES) and compared to experimental results. Both self-excited longitudinal $(100 \mathrm{~Hz})$ and transverse $(1400 \mathrm{~Hz})$ modes observed in the experiments are captured by LES and instability mechanisms are discussed. LES results for all modes are compared to a Helmholtz solver output, showing that the transverse mode appearing in the LES is the $1 L x$-2Ty-0Tz eigenmode of the chamber, affecting the velocity field symmetrically. The $1 L x$ fluctuation causes a symmetric flame roll-up which increases heat release rate fluctuations, closing the feedback loop. The 2Ty component of the mode is active along the flame holder axis and causes not only transverse fluctuations but also a reorganization of the mean flame along two main zones located on both sides of the zero acoustic velocity plane, a feature that has not been reported before. Dynamic mode decomposition (DMD) is used to extract the structure of the transverse mode from LES snapshots which is found to match the Helmholtz solver prediction. This study confirms the capacity of highorder LES to capture not only low-frequency oscillations but also high-order frequency transverse modes in combustion chambers.
\end{abstract}

\section{Introduction}

The need for more efficient propulsion systems and energy generation leads to the development of lean premixed combustion [1,2]. One main drawback of lean premixed flames is that they can exhibit combustion instabilities: flow and flame disturbances interact with the resonant modes of the combustion chamber, generating large pressure oscillations and leading to engine failure.

The prediction of combustion instabilities remains an open task which impacts especially the predesign stage of combustion systems [3]. Experimental campaigns ranging from laminar [4,5] to highly turbulent flames [6,7] in academic and heavy-duty industrial configurations, provide better understanding of fundamental mechanisms. However, most studies of combustion instabilities focus on longitudinal low-frequency modes [8,9] for which theory, experiments and simulations have been extensively developed. For transverse highfrequency instabilities (such as screech in afterburners, rocket engines or in certain gas turbines), much less work is available and even theory is still not complete today [10-14]. In this context, the Volvo configuration developed in the early 1990s is a good prototype to

\footnotetext{
* Corresponding author.

E-mail address: ghani@cerfacs.fr (A. Ghani).
}

investigate combustion instability, both at low and high frequency: beside stable operation (for which velocity fields were measured), self-excited longitudinal and transverse combustion instabilities were observed during experimental testing [15-17].

The experimental data base for the Volvo setup offers a large validation base for numerical simulation [18]. While URANS (Unsteady Reynolds-Averaged Navier-Stokes) and LES have already been used to study combustion instabilities in the Volvo configuration [19-21], most previous studies have concentrated on the low-frequency longitudinal mode appearing around $100 \mathrm{~Hz}$ in this configuration (buzz mode). Except for the work of Jourdain and Eriksson [22,23] who used URANS as well as linearized Navier Stokes equations to investigate both low-frequency and high-frequency modes, much less studies have addressed the other unstable mode, called screech [10,24], at $1400 \mathrm{~Hz}$ which also appears in this setup. One objective of the present work is to focus on this high-frequency transverse mode and capture it with high-order LES.

Screech was first encountered in the late 1940s during rocket engine operation. It is characterized by large pressure amplitudes in the high-frequency $(\mathrm{kHz})$ range and high-pitched screeching sound. It can destroy the combustor within seconds [24]. Screech is associated to transverse (tangential and radial) acoustic modes propagating between the lateral walls of the combustion chamber. Contrary to longitudinal [8] or azimuthal [25] modes, transverse modes are both 


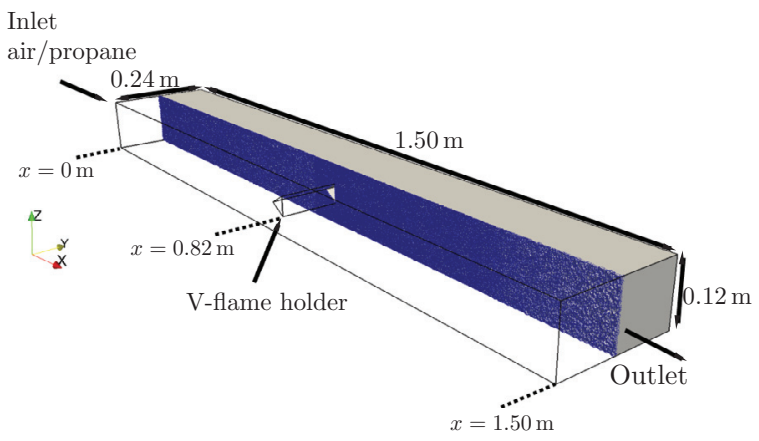

Fig. 1. Middle cut plane of the mesh in the computational domain.

difficult to predict and dangerous in practice because they can reach very high oscillation levels. While LES has been shown to capture longitudinal modes 19,26,27,28] as well as azimuthal modes [29,30], it seems to be more difficult to capture transverse modes: these modes obviously involve higher frequencies, smaller vortices and request an increased precision. Here we show that high-order compressible LES can capture both longitudinal and transverse modes.

The paper is organized as follows: Section 2.1 presents the target configuration followed by its acoustic characterization in Section 2.2. To do so, a 3D Helmholtz solver is used to provide all modes of the set-up before performing LES. After the presentation of the LES solver (Section 3), the simulation is validated against experimental data for both non-reacting and reacting flows (Section 4). Sections 5 and 6 compare LES and experimental observations of self-excited longitudinal and transverse modes, respectively. The resulting pressure amplitudes and phases are also compared to the Helmholtz solver predictions to identify the mode natures.

\section{Target configuration}

\subsection{Geometry}

The Volvo configuration consists of a rectangular chamber of constant cross section $(0.12 \mathrm{~m} \times 0.24 \mathrm{~m})$ and a bluff body for flame stabilization (Fig. 1). The total length of the configuration is $1.50 \mathrm{~m}$. The flame holder is an equilateral triangle with an edge length of $0.04 \mathrm{~m}$ mounted $x=0.82 \mathrm{~m}$ downstream of the inlet. Two elements which were not clearly characterized in the experiments (fuel feeding line and honeycomb) are not considered in the simulations since their impact on the results is marginal, as will be shown in the next sections.

\subsection{Combustor acoustics}

Since the objective of this work is to capture chamber modes, it is useful to compute these before performing LES. The 3D Helmholtz code AVSP [31] is first used. It solves the linearized Euler equations by assuming small perturbations as:

$\gamma p_{0} \nabla \cdot\left(\frac{1}{\rho_{0}} \nabla \hat{p}\right)+\omega^{2} \hat{p}=0$

where the variables $p_{0}, \hat{p}, \omega$ and $\gamma$ are the mean pressure, fluctuations of pressure, pulsation and specific heat ratio, respectively. The outlet pressure is imposed $\left(p^{\prime}=0\right)$ whereas the inlet and the walls are zero velocity fluctuation boundaries $\left(u^{\prime}=0\right)$. The sound speed field $c_{0}$ and the density $\rho_{0}$ fields correspond to cold gases in the plenum $(T=288 \mathrm{~K})$ from $x=0$ to $0.82 \mathrm{~m}$ and burnt gases in the chamber $(T=1900 \mathrm{~K})$ from $x=0.82$ to $1.50 \mathrm{~m}$. The computations were performed with variable specific heat ratio $\gamma$ and mean pressure $p_{0}=1$ bar.

The modes found by AVSP are summarized in Table 1 and displayed in Figs. 2 and 3. The first longitudinal mode $(1 L x-0 T y-0 T z)$ is
Table 1

Frequencies of modes given by the Helmholtz solver and comparison with the mode frequency found in the LES. The mode name consists of the number of pressure nodes in $x$-direction $(n L x), y$-direction ( $p T y)$ and $z$-direction $(q T z)$. The experimental frequencies are reported by Sjunnesson et al. [16] whereas all the other frequencies are obtained in the present study.

\begin{tabular}{lcll}
\hline $\begin{array}{l}\text { Mode name } \\
{[n L x-p T y-q T z]}\end{array}$ & $\begin{array}{l}\text { Helmholtz } \\
\text { solver }[\mathrm{Hz}]\end{array}$ & LES $[\mathrm{Hz}]$ & Experiment $[\mathrm{Hz}]$ \\
\hline 1 Lx-0Ty-0Tz & 88 & 95 & 100 \\
$2 L x-0 T y-0 T z$ & 251 & - & - \\
$3 L x-0 T y-0 T z$ & 374 & - & - \\
$1 L x-1 T y-0 T z$ & 765 & - & - \\
$1 L x-0 T y-1 T z$ & 1418 & - & - \\
$1 L x-2 T y-0 T z$ & 1418 & 1360 & 1400 \\
\hline
\end{tabular}

a typical quarter wave mode (Fig. 3) at $88 \mathrm{~Hz}$. This mode has been observed during experiments (at $100 \mathrm{~Hz}$ ) as well as in LES $(95 \mathrm{~Hz})$ and is often referred to as the "buzz" mode. The first transverse mode (1Lx$1 T y-0 T z)$ is found at a frequency of $765 \mathrm{~Hz}$ and was observed neither in the experiments nor in the LES. Two transverse modes are found at $1418 \mathrm{~Hz}$ (Fig. 3): the reason for this is the ratio of width to height in the chamber (equal to 2) which leads to this result. In the LES only the $1 L x-2 T y-0 T z$ mode was found at a frequency of $1360 \mathrm{~Hz}$. The mode frequency encountered during experiments was $1400 \mathrm{~Hz}$.

\section{Large eddy simulation methodology}

\subsection{Numerical setup}

Four different cases are studied in this work (Table 2). All correspond to cases tested in the experiments: non-reacting, reacting stable, reacting low-frequency unstable (buzz) and reacting highfrequency unstable (screech). All simulation parameters are kept equal for the different cases except the inlet velocity $u_{\text {bulk }}$ and the global equivalence ration $\phi$. A fully compressible high-order code $[32,33]$ is used for LES which solves the reactive multi-species Navier-Stokes equations on unstructured grids. The two-step TaylorGalerkin finite-element convection scheme [32] provides at least third-order accuracy in time and space. The Sigma model [34] is used to model the sub-grid stress tensor. The dynamic thickened flame model describes flame/turbulence interactions $[28,35,36]$ with the model of Charlette et al. [37] for the subgrid efficiency.

Special attention is needed for inlet and outlet boundary conditions as they control combustion instabilities: they are treated with Navier-Stokes Characteristic Boundary Conditions (NSCBC) [38-40]. The outlet is modeled as a reflecting section $\left(p^{\prime}=0\right)$ with the $3 \mathrm{D}$ NSCBC version derived by Granet et al. [39]. The inlet is located at $x=0$ in Fig. 1 (Section 3.3). It acts acoustically as a $u^{\prime}=0$ surface but

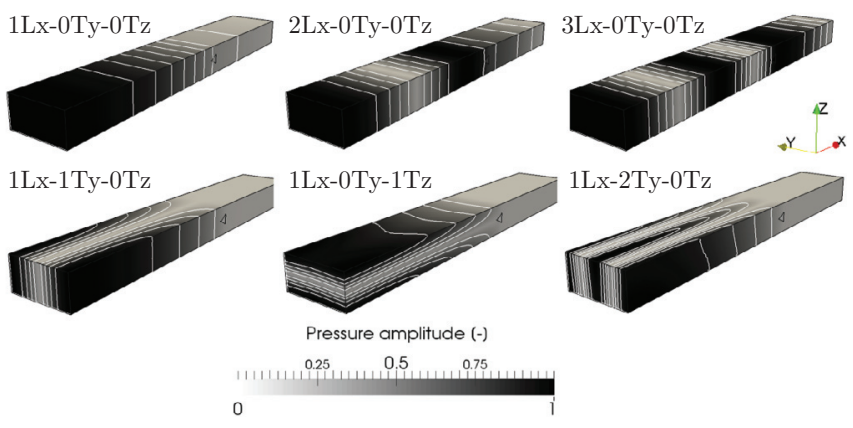

Fig. 2. Pressure amplitudes of the first five modes obtained by the Helmholtz solver The mode name consists of the number of pressure nodes in $x$-direction $(n L x), y$ direction ( $p T y)$ and $z$-direction ( $q T z)$. 

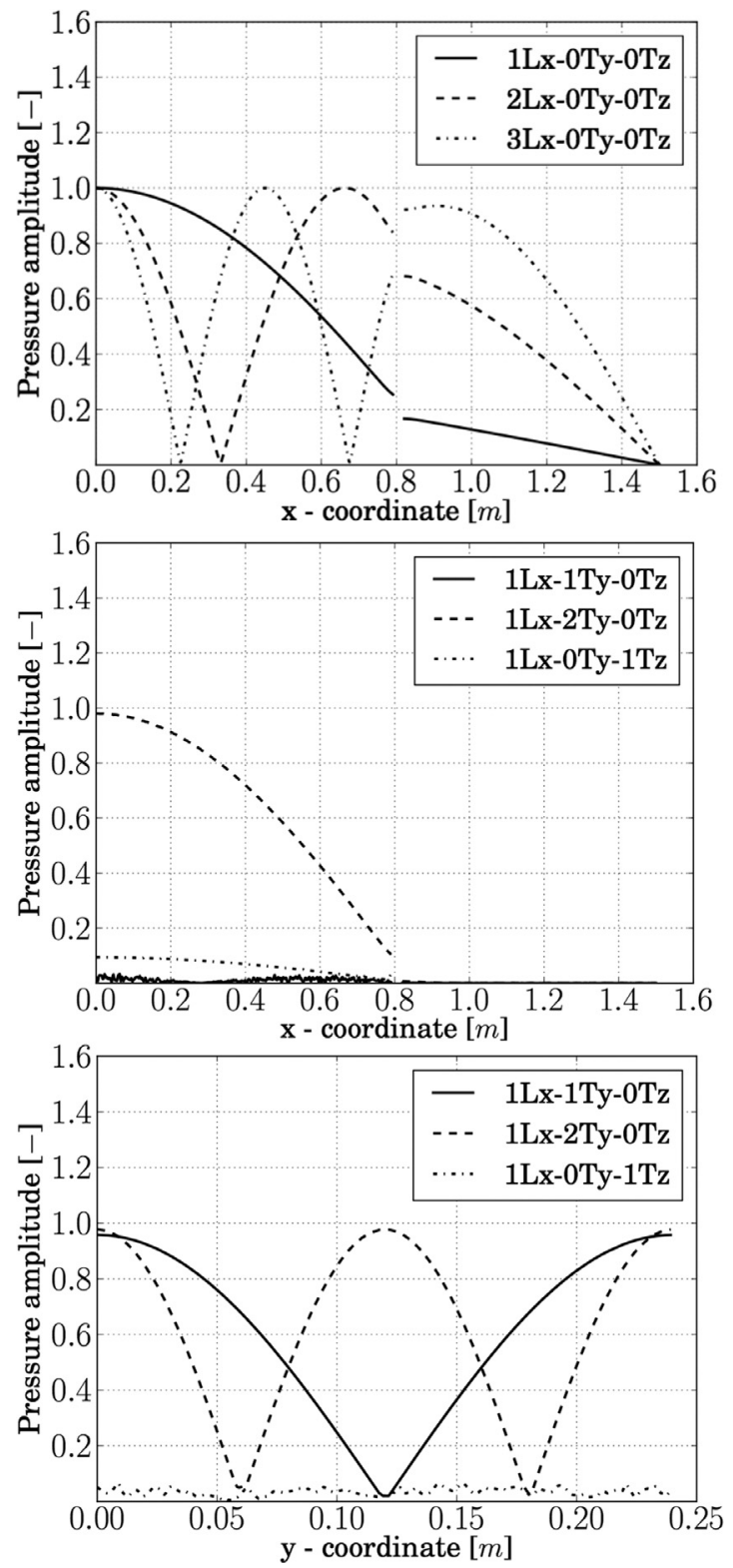

Fig. 3. Pressure amplitudes of the first five modes obtained by the Helmholtz solver. Top: First three longitudinal modes. Mode structure along axial centerline at $y=$ $0.12 \mathrm{~m}$. Middle: Longitudinal part of transverse modes plotted at same position as top image. Bottom: Pressure amplitude along $y$-coordinate at $x=0.05 \mathrm{~m}$.

Table 2

Definition of operating conditions.

\begin{tabular}{lllll}
\hline Case & $u_{\text {bulk }}[\mathrm{m} / \mathrm{s}]$ & $\phi[-]$ & $T_{u}[\mathrm{~K}]$ & Mode topology \\
\hline Non-reacting & 16.6 & 0.0 & 288 & - \\
Reacting stable & 17.3 & 0.65 & 288 & - \\
Buzz & 17.3 & 0.95 & 288 & $1 \operatorname{Lx}-0 \mathrm{Ty}-0 \mathrm{Tz}\left(f_{b}=95 \mathrm{~Hz}\right)$ \\
Screech & 36.0 & 0.72 & 288 & $1 \operatorname{Lx}-2 \mathrm{Ty}-0 \mathrm{Tz}\left(f_{s}=1360 \mathrm{~Hz}\right)$ \\
\hline
\end{tabular}

is also used to inject turbulence using the method of Guezennec and Poinsot [40]. The walls are modeled as adiabatic no-slip walls.

The middle cut plane of the mesh is shown in Fig. 1. The fully tetrahedral mesh contains $36,85,066$ nodes and 209,19,678 cells. The mesh size in the reaction zone and further downstream is $2 \mathrm{~mm}$ which ensures the resolution of at least $80 \%$ of the kinetic energy of the flow [41]. This resolution leads to different dynamic thickening factors and efficiency values for the different flames (Table 3). For tur-
Table 3

Maximum thickening and efficiency values for each reacting case.

\begin{tabular}{lccc}
\hline & Stable case & Buzz case & Screech case \\
\hline Thickening & 15 & 25 & 20 \\
Efficiency & 3 & 6 & 4.5
\end{tabular}

\section{Table 4}

Constants of pre-exponential factor $\mathcal{A}_{j}$ and activation energies $E_{j}$ for chemistry modeling.

\begin{tabular}{lll}
\hline & $\mathcal{A}_{j}[\mathrm{cgs}]$ & $E_{j}[\mathrm{cal} / \mathrm{mol}]$ \\
\hline Reaction 1 & $2.0 \times 10^{12}$ & $3.3 \times 10^{3}$ \\
Reaction 2 & $4.5 \times 10^{10}$ & $1.2 \times 10^{3}$ \\
\hline
\end{tabular}

bulent premixed cases the flame thickness depends on the laminar flame speed [42] which is different for each operating point. Due to the fixed mesh size, the thickening values differ for each case depending on the equivalence ratio. The near wall region of the flame holder and the boundary walls feature dimensionless wall distances of $y^{+}=55$ at the highest velocity levels (screech case). The time step is fixed for each case and corresponds to an acoustic CFL number of 0.7 .

\subsection{Chemical kinetics}

Chemistry is computed using a reduced two-step mechanism for propane/air flames taking six species into account $\left(\mathrm{C}_{3} \mathrm{H}_{8}, \mathrm{O}_{2}, \mathrm{CO}_{2}\right.$, $\mathrm{CO}, \mathrm{H}_{2} \mathrm{O}$ and $\mathrm{N}_{2}$ ):

$$
\begin{aligned}
& \mathrm{C}_{3} \mathrm{H}_{8}+3.5 \mathrm{O}_{2} \longrightarrow 3 \mathrm{CO}+4 \mathrm{H}_{2} \mathrm{O} \\
& \mathrm{CO}+0.5 \mathrm{O}_{2} \longleftrightarrow \mathrm{CO}_{2}
\end{aligned}
$$

The reaction rates $q_{j}$ follow an Arrhenius law [2]:

$$
\begin{aligned}
& q_{1}=\mathcal{A}_{1}\left(\frac{\rho Y_{\mathrm{C}_{3} \mathrm{H}_{8}}}{W_{\mathrm{C}_{3} \mathrm{H}_{8}}}\right)^{0.9028}\left(\frac{\rho Y_{\mathrm{O}_{2}}}{W_{\mathrm{O}_{2}}}\right)^{0.6855} \exp \left(\frac{-E_{a, 1}}{R T}\right) \\
& q_{2}=\mathcal{A}_{2}\left[\left(\frac{\rho Y_{\mathrm{CO}}}{W_{\mathrm{CO}}}\right)^{1.0}\left(\frac{\rho Y_{\mathrm{O}_{2}}}{W_{\mathrm{O}_{2}}}\right)^{0.5}-\frac{1}{K}\left(\frac{\rho Y_{\mathrm{CO}_{2}}}{W_{\mathrm{CO}_{2}}}\right)^{1.0}\right] \exp \left(\frac{-E_{a, 2}}{R T}\right)
\end{aligned}
$$

The pre-exponential constants $\mathcal{A}_{j}$ and the activation energies $E_{j}$ are given in Table 4 and $K$ is the equilibrium constant given by Kuo [43]. This two-step scheme was validated against the GRI-MECH 3.0 mechanism (Fig. 4) using CANTERA. Flame speeds and adiabatic temperatures of the burnt gases are accurately reproduced for a 1D planar flame using DNS. The operating conditions are equivalent to those used for the target configuration $\left(T_{0}=288 \mathrm{~K}\right.$ and $\left.p_{0}=101325 \mathrm{~Pa}\right)$.

\subsection{Turbulence injection}

The honeycomb and the fuel support line (present in the experiments) are not considered in the LES. A perfectly premixed propane/air mixture with a superimposed homogeneous isentropic turbulence level is injected at the inlet. The turbulence intensity of the inlet section is equivalent to $8 \%$ of the bulk velocity and decreases at the honeycomb position to $3 \%$ which corresponds to data obtained by measurements at this position [17]. The integral length scale of the imposed turbulent field is $0.03 \mathrm{~m}$ at the injection plane $(x=0 \mathrm{~m})$ corresponding to one quarter of the chamber height. Figure 5 displays an instantaneous field of vorticity in the central plane of the chamber. 

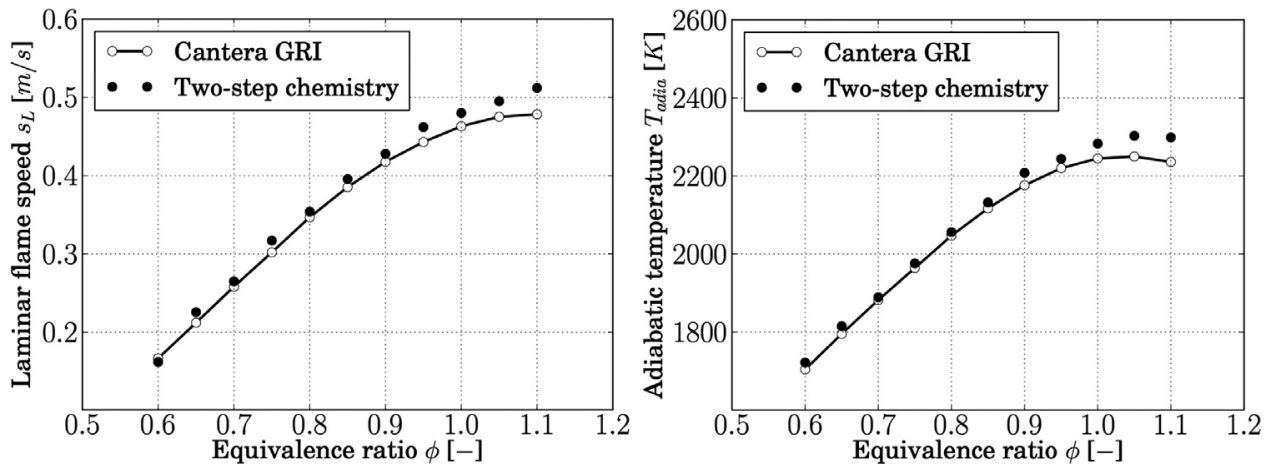

Fig. 4. Comparison of GRI-Mech 3.0 and two-step chemistry for laminar flame speed and adiabatic temperature of the burnt gases.

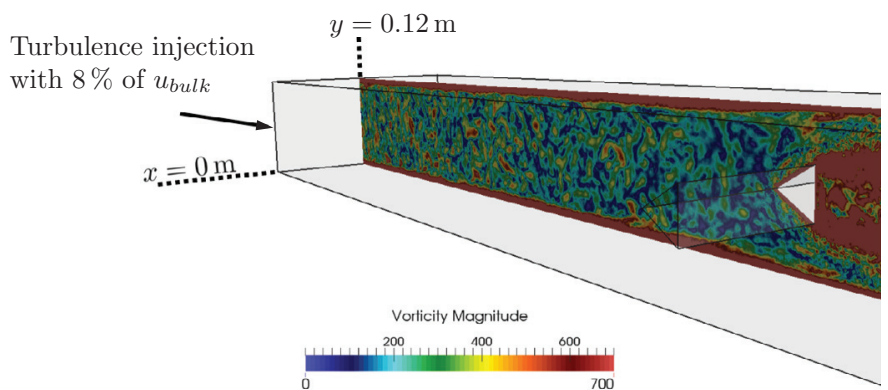

Fig. 5. Plane of vorticity field showing the injected turbulence in the 3D domain.

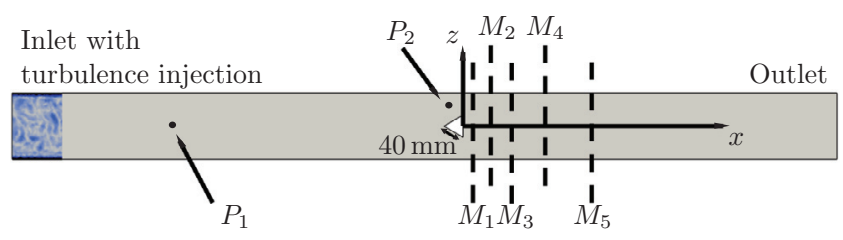

Fig. 6. Middle cut plane of the geometry with measurement planes $M_{1}-M_{5}$.

\section{Validation of the stable cases}

LES results are first validated against experimental results for the stable validation cases. This is done in two steps: first, cold flow results for axial and transverse velocities are compared. In a second step, experimental data for the stable reacting flow is used to validate LES. Figure 6 displays the measurement planes for velocities $M_{1}-M_{5}$ where experimental data were recorded and compared to LES results. The time step was fixed at $3.5 \times 10^{-7} \mathrm{~s}$ which corresponds to a CFL number of the order of 0.7. The cost for the stable reacting case was about $80,000 \mathrm{CPU}$ hours for $320 \mathrm{~ms}$ of physical time on 128 Intel Sandy Bridge processors.

\subsection{Non-reacting case}

The non-reacting flow $\left(u_{\text {bulk }}=16.6 \mathrm{~m} / \mathrm{s}\right)$ is averaged for $320 \mathrm{~ms}$ corresponding to four convective flow through times in the whole chamber. Axial and transverse velocities are in good agreement (Fig. 7) for all measurement plane positions. RMS profiles for both axial and transverse velocities are also well reproduced (Fig. 8). The recirculation zone is well captured as confirmed by the axial velocity
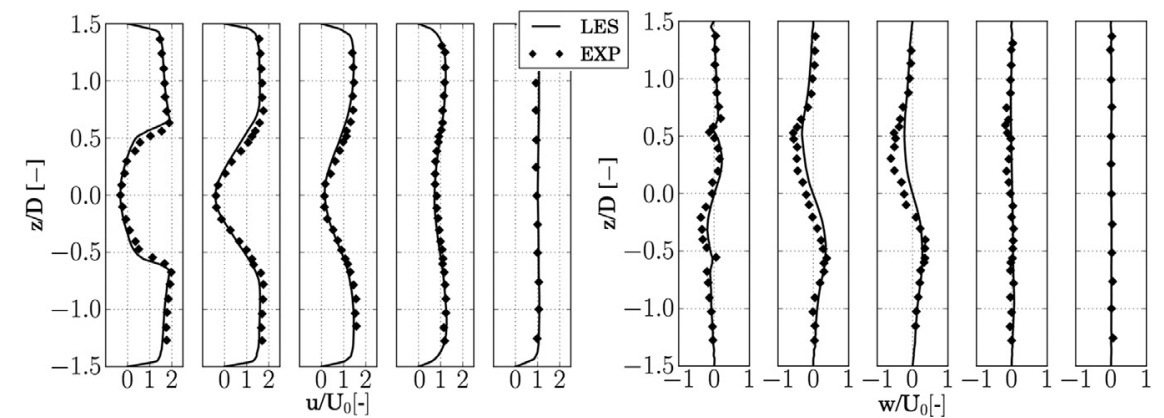

Fig. 7. Non-reacting case velocities at measurement planes $M_{1}-M_{5}$. Left: Normalized axial velocities. Right: Normalized transverse velocities.

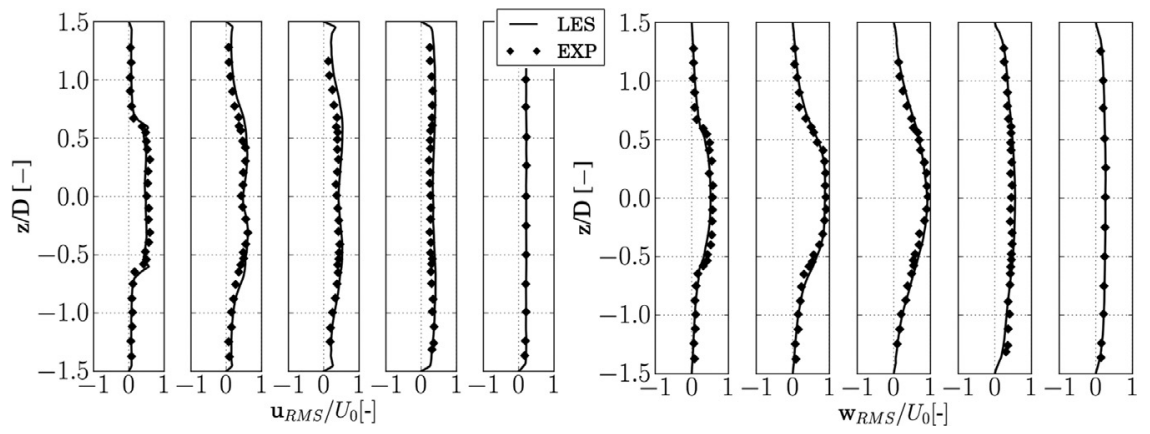

Fig. 8. Non-reacting case velocities at measurement planes $M_{1}-M_{5}$. Left: Normalized axial RMS velocities. Right: Normalized transverse RMS velocities. 


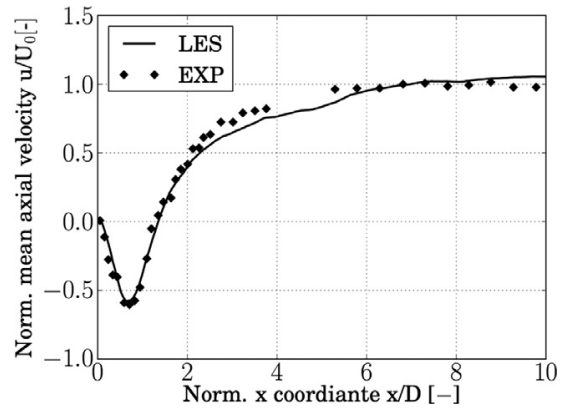

Fig. 9. Axial velocity for the non-reacting case starting from the bluff body.
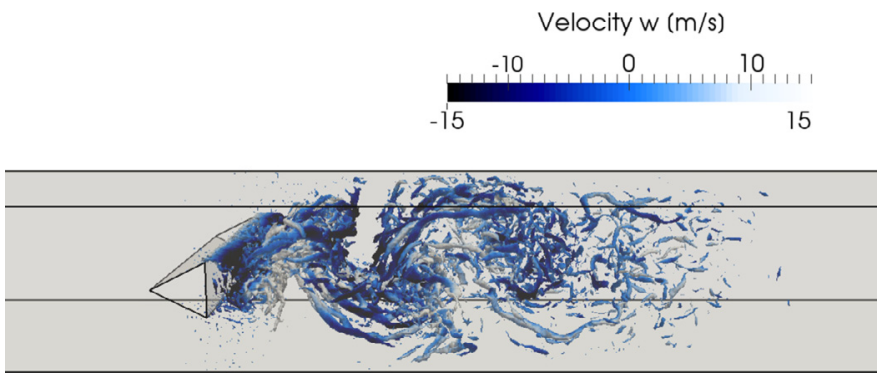

Fig. 10. Vortex shedding structure for the non-reacting case visualized by an isocontour of $Q_{\text {crit }}=2 \times 10^{8} \mathrm{~s}^{-1}$ colored by transverse velocity w.

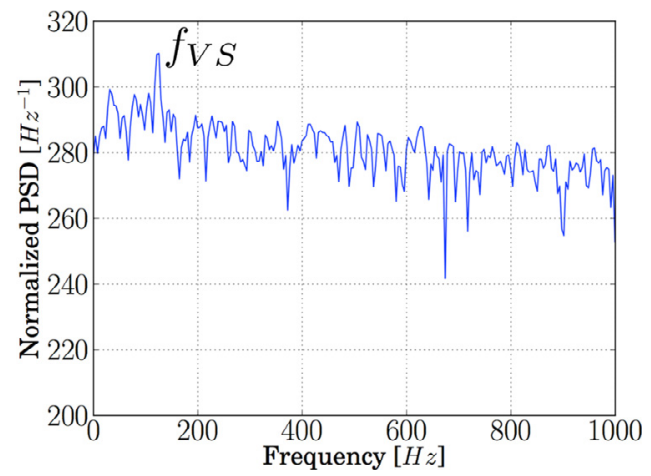

Fig. 11. Frequency $f_{\mathrm{VS}}=120 \mathrm{~Hz}$ of the transverse velocity $\mathrm{w}$ recorded behind the bluff body evidencing the vortex shedding. The signal is normalized by its mean value.

profile on the chamber axis (Fig. 9). During the non-reacting test, vortex shedding appears behind the bluff body and its frequency was determined experimentally to $f_{\mathrm{VS}}=105 \mathrm{~Hz}$. In Fig. 10 the shedding encountered in the LES is visualized exhibiting a Von Kármán-like flow motion. Its frequency can be determined from the transverse velocity component in $z$-direction behind the flame holder at the same position as in the experiments $(x=0.82 \mathrm{~m})$. The power spectrum density of the normalized signal is given in Fig. 11 and the frequency of vortex shedding in the LES is found to be $f_{\mathrm{VS}}=120 \mathrm{~Hz}$ (frequency error of \pm $5 \mathrm{~Hz}$ due to the discrete time signal) close to the experimental value (105 Hz).

\subsection{Reacting case}

The first reacting case is the stable run of Table $2\left(u_{\text {bulk }}=17.3 \mathrm{~m} / \mathrm{s}\right.$, $\phi=0.65)$. The averaging time is equal to the non-reacting case (320 ms). Experimental and numerical axial ( $x$-direction) and transverse ( $z$-direction) velocity components match well for both mean (Fig. 12) and RMS (Fig. 13) quantities. The recirculation zone is larger compared to cold flow profiles and is well captured by LES (Fig. 14). Slight under predictions of the recirculation velocity are observed for both components as obtained using other LES codes [18].

\section{Longitudinal modes: The buzz case}

The first unstable regime computed with LES is the buzz case in Table $2\left(u_{\text {bulk }}=17.3 \mathrm{~m} / \mathrm{s}, \phi=0.95\right)$, where a longitudinal mode appears at $100 \mathrm{~Hz}$ in the experiment. LES was run for $0.1 \mathrm{~s}$ corresponding to 10 buzz cycles with a fixed time step $\Delta t=2 \times 10^{-7} \mathrm{~s}$ corresponding to a CFL number of the order of 0.7. The simulation cost was 40,000 CPU hours on 128 Intel Sandy Bridge processors. After initialization of the reacting flow, pressure fluctuations grow in time, propagate periodically in the combustor and establish a limit cycle. These axial perturbations cause large heat release fluctuations (Fig. 15, left) and feed the instability mechanism. The frequency of these oscillations in the LES is $f_{b}=95 \mathrm{~Hz}$ (Fig. 15, right). Both pressure and heat release signals are in phase and energy is added to the acoustic field as stated through the Rayleigh criterion [44].

Further insight into the buzz mode structure can be obtained by using DMD [45] on 3D solution fields. These are recorded over a period of $0.04 \mathrm{~s}$ corresponding to 5 buzz mode cycles (150 snapshots). Pressure amplitude and phase are extracted from DMD results on the middle plane axis ( $y=0.12 \mathrm{~m}$ ) and compared to the Helmholtz solver results presented in Section 2.2. Results (Fig. 16) show good agreement: the phase is quasi-constant over the whole set-up indicating a standing mode. The modulus corresponds to a quarter-wave mode of the whole setup. Instantaneous images of numerical Schlieren reconstructed fields are compared to experimental images during one oscillation cycle (Fig. 17). The flapping motion reveals flame perturbations induced by the longitudinal acoustic mode. The roll up of the shear layers and the shape of the flame are very well reproduced by the LES.

\section{High-frequency transverse oscillations: The screech case}

To trigger screech, the bulk velocity has to reach $u_{\text {bulk }}=36 \mathrm{~m} / \mathrm{s}$ (Table 2). The initialization of this case is realized as follows: starting from the stable reacting flow of Section $4\left(u_{\text {bulk }}=17.3 \mathrm{~m} / \mathrm{s}\right.$,
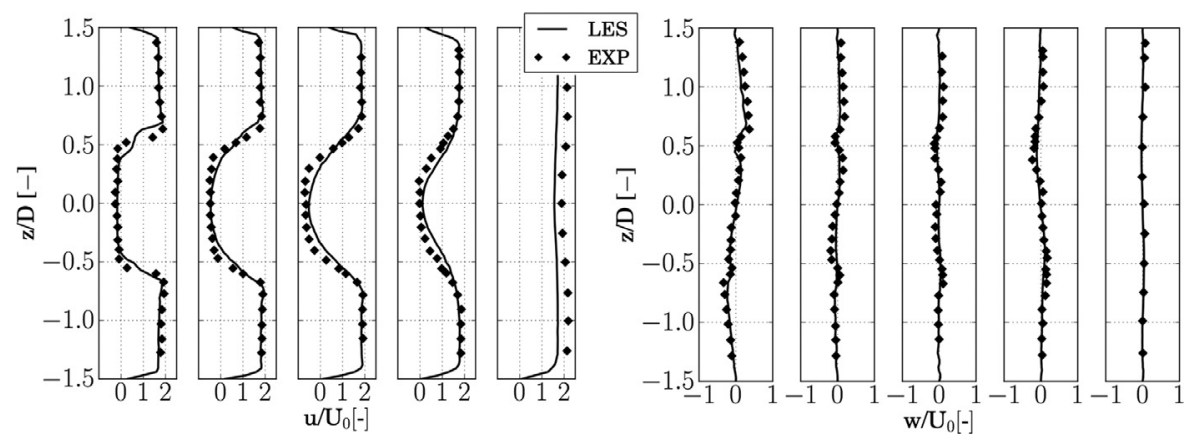

Fig. 12. Stable reacting case velocities at measurement planes $M_{1}-M_{5}$. Left: Normalized axial velocities. Right: Normalized transverse velocities. 


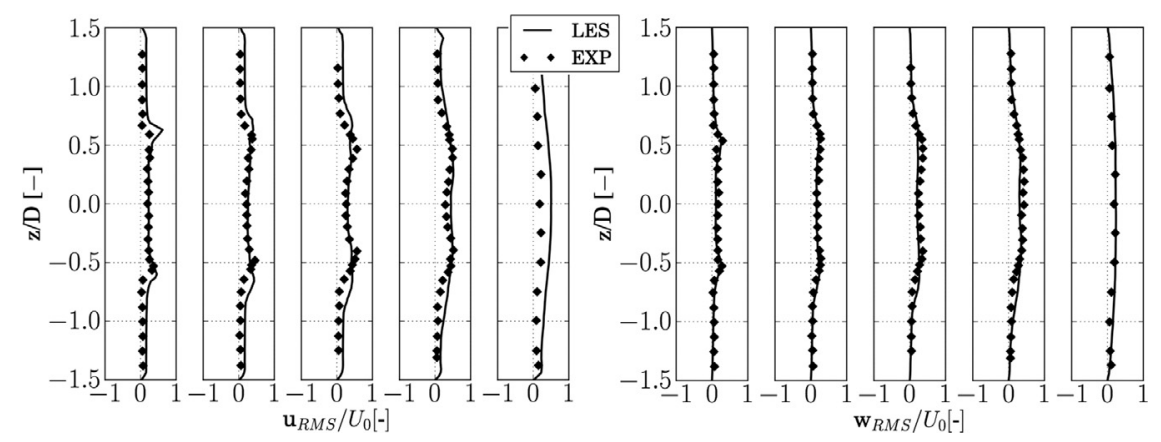

Fig. 13. Stable reacting case velocities at measurement planes $M_{1}-M_{5}$. Left: Normalized axial RMS velocities. Right: Normalized transverse RMS velocities.

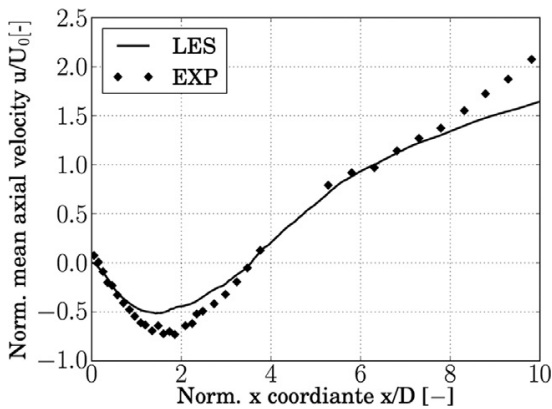

Fig. 14. Axial velocity for the stable reacting case starting from the bluff body.

$\phi=0.65)$, the inlet mass flow rate is augmented to the target inlet velocity $\left(u_{\text {bulk }}=36 \mathrm{~m} / \mathrm{s}\right.$ ) and, at the same time, the equivalence ratio is changed to $\phi=0.72$. As soon as the screech regime is reached, the LES becomes unstable without any forcing. LES was run for 22 ms corresponding to 30 screech cycles. The time step was fixed at

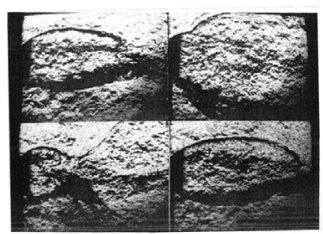

Experiment

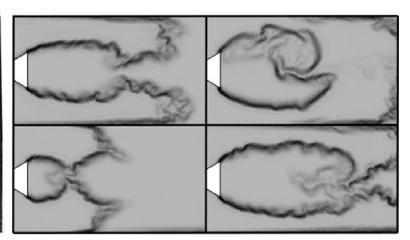

Large Eddy Simulation
Fig. 17. Comparison of low frequency oscillation. Left: Flash Schlieren from experiments. Right: Derivative of density from instantaneous LES solutions.

$3.3 \times 10^{-7} \mathrm{~s}$ for a CFL number of the order of 0.7 . The computational cost was about 8000 CPU hours on 128 Intel Sandy Bridge processors.

Pressure fluctuations at probe $P_{1}$ (Fig. 6) encountered during the limit cycle are shown in Fig. 18. A very coherent pattern is observed where high-frequency oscillations are present with large amplitudes (1500 Pa). Spectral analysis (Fig. 18, right) confirms that the highfrequency mode corresponds to the screech frequency $f_{s}(1360 \mathrm{~Hz})$ [16]. Figure 19 displays instantaneous snapshots of transverse velocity $z$, temperature and vorticity highlighting the symmetric
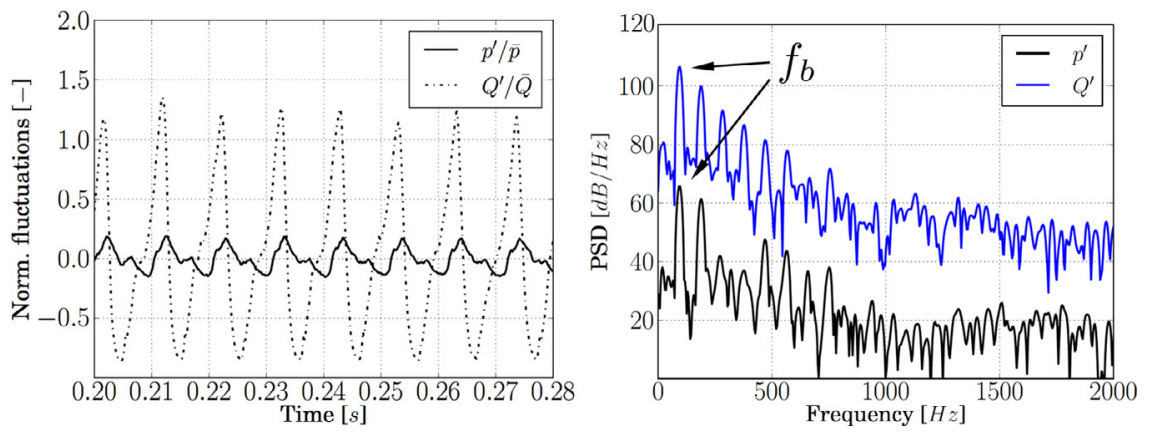

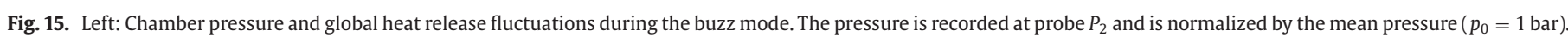

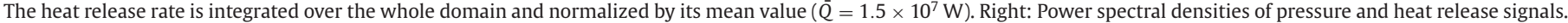
Pressure recorded at probe $P_{2}$ (Fig. 6).
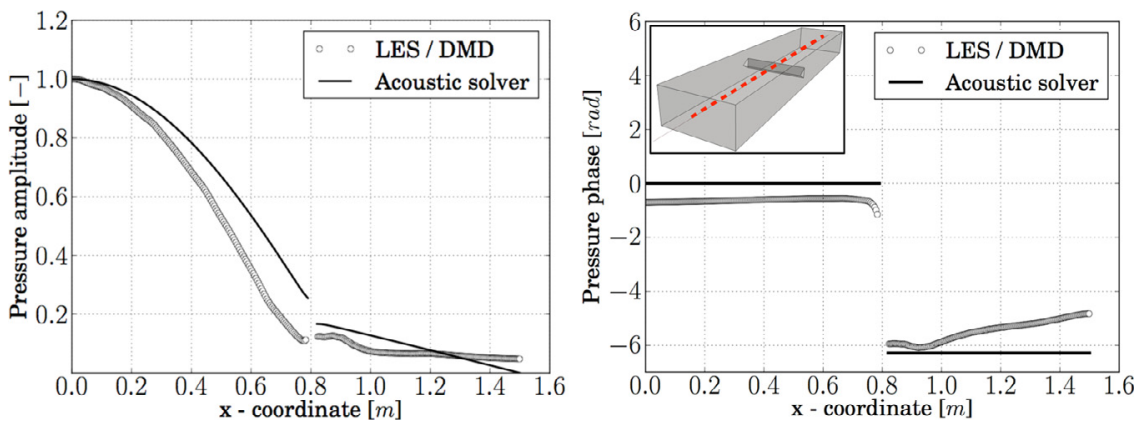

Fig. 16. Comparison of mode structure at $132 \mathrm{~Hz}$ obtained via DMD of LES data and acoustic solver (AVSP). Left: Pressure modulus. Right: Pressure phase. 

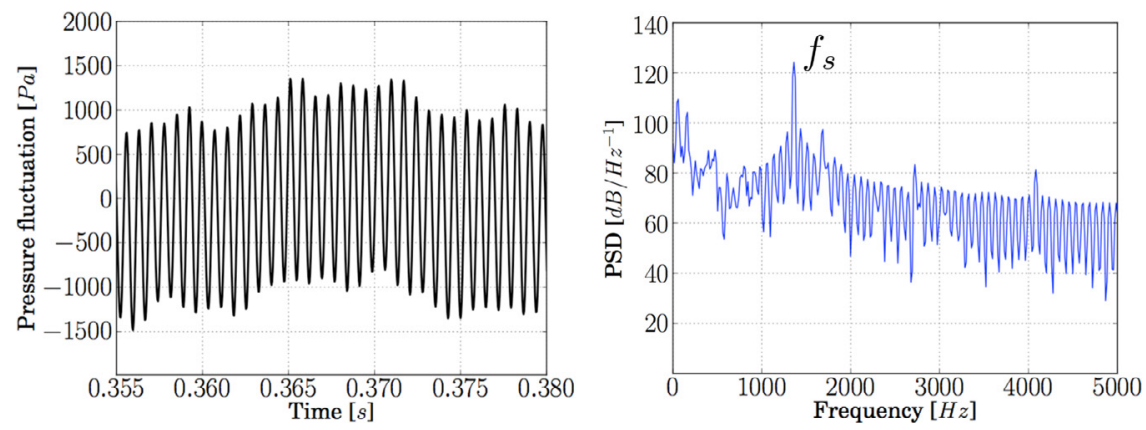

Fig. 18. Left: Pressure fluctuations measured at probe $P_{1}$. Right: Power spectral density of the pressure signal.

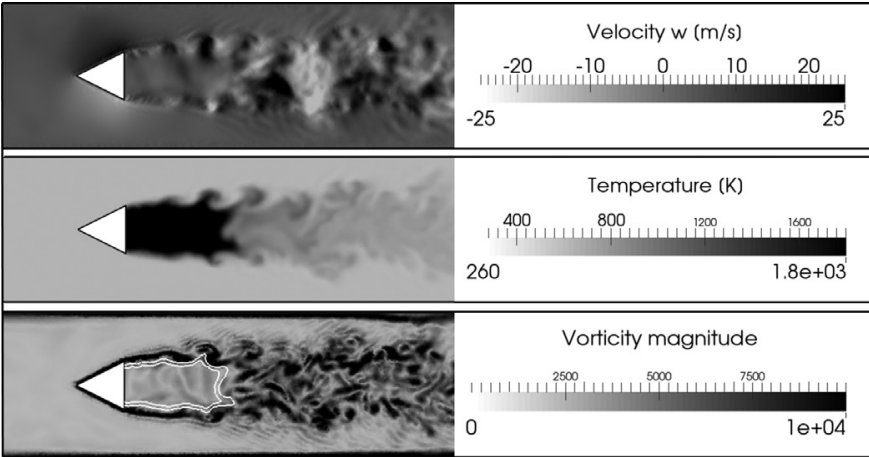

Fig. 19. Instantaneous snapshots of the transverse velocity $w$ (top), temperature (middle) and vorticity (bottom) during screech $\left(f_{s}=1360 \mathrm{~Hz}\right)$. Contour of instantaneous heat release $\dot{Q}=2 \times 10^{8} \mathrm{Wm}^{-3}$.

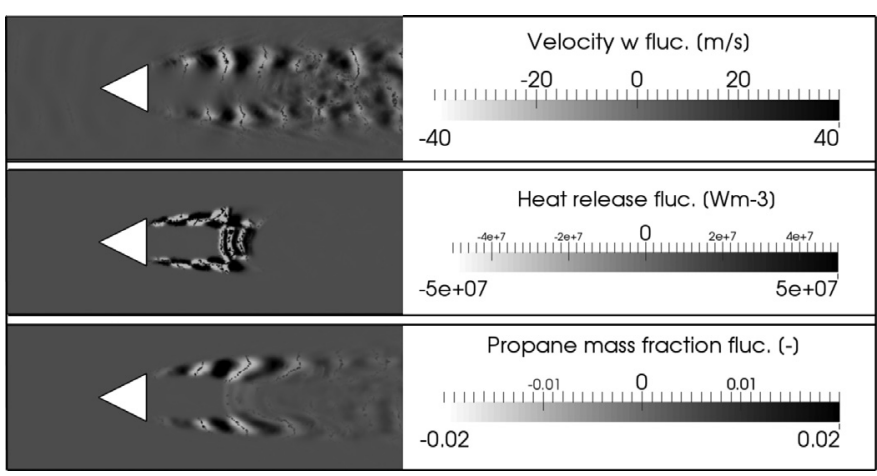

Fig. 20. Fluctuations of transverse velocity (top), heat release (middle) and propane (bottom) extracted from a series of instantaneous solutions by DMD for the screech case $\left(f_{s}=1360 \mathrm{~Hz}\right)$.

pattern in each of these fields. To isolate the $1360 \mathrm{~Hz}$ transverse mode, flow characteristics at the screech mode frequency are extracted from LES data using DMD (Fig. 20). Its application to a solution series of 8 cycles (240 snapshots) reveals a symmetric pattern of perturbations for transverse velocity in $z$-direction (top), heat release (middle) and propane (bottom) showing that these motions are caused by the $1 L x-2 T y-0 T z$ transverse mode and that the source of the fluctuations of heat release is located very close to the flame holder in the recirculation zone. Unlike the screech mode observed by Rogers and Marble [10], this mode is transverse but causes symmetric flow pattern. Rogers screech mode produced sinusoidal motions of the flame holder wake whereas here, the 1 Lx component of the 1 Lx-2Ty-0Tz mode produces a varicose motion of the wake where transverse velocities have opposite signs in the top and bottom parts of the chamber while heat release and fuel mass fractions fluctuate with symmetric shapes. These motions are induced by the $1 L x$ part of the trans-

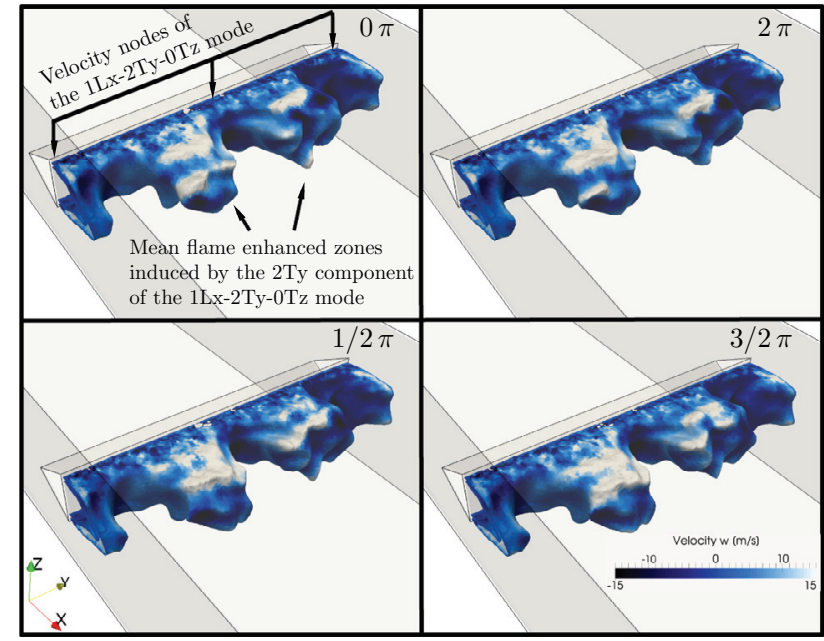

Fig. 21. Instantaneous heat release rate (iso-surface at $\dot{Q}=7 \times 10^{7} \mathrm{Wm}^{-3}$ ) during one screech cycle colored by the velocity $w$ (in $z$-direction).

verse mode which can be explained by the mode conversion process described by Palies et al. [46]: pressure fluctuations impinge on the flame holder and generate vortices in $x$ - and $z$-directions leading to symmetric flow patterns.

Instantaneous heat release rates during one instability cycle (Fig. 21) indicate that the flame brush is also influenced by the 2Ty component of the mode. The flame is pulsating at the mode frequency but even its mean shape is affected by the transverse component of the mode along the $y$-direction: Fig. 21 reveals that the flame shape exhibits two major reaction zones, located on both sides of the central velocity node. Acoustic velocity fluctuations in $y$-direction (velocity $v$ ) are plotted for one screech cycle in Fig. 22 using DMD data. These reach maximum values near the inlet, propagate downstream and perturb the flame. This decomposition highlights the two-dimensional influence of the mode, where flow and flame field are affected longitudinally (symmetric patterns) as well as transversally by flame deformation.

A very specific feature of this mode is that reaction rates fluctuate at the screech frequency (Fig. 22) as expected in an unstable case but even the mean flame shape is affected by the mode, leading to the two large reaction zones visible on Figs. 21 and 22.

To verify that the mode observed in the LES is indeed the $1 L x$ 2Ty-0Tz mode predicted by the Helmholtz solver, pressure and velocity fields extracted from DMD of the LES solutions at $1360 \mathrm{~Hz}$ are compared to the output of the Helmholtz solver for the $1 L x$ 2Ty-0Tz mode (Fig. 23). Amplitude and phase in transverse direction for pressure (Fig. 23 (top)) and velocity $v$ (Fig. 23 (bottom)) agree very well whereas LES data in the chamber (Fig. 24) are more noisy: the LES field includes hydrodynamic pressure fluctuations while the 


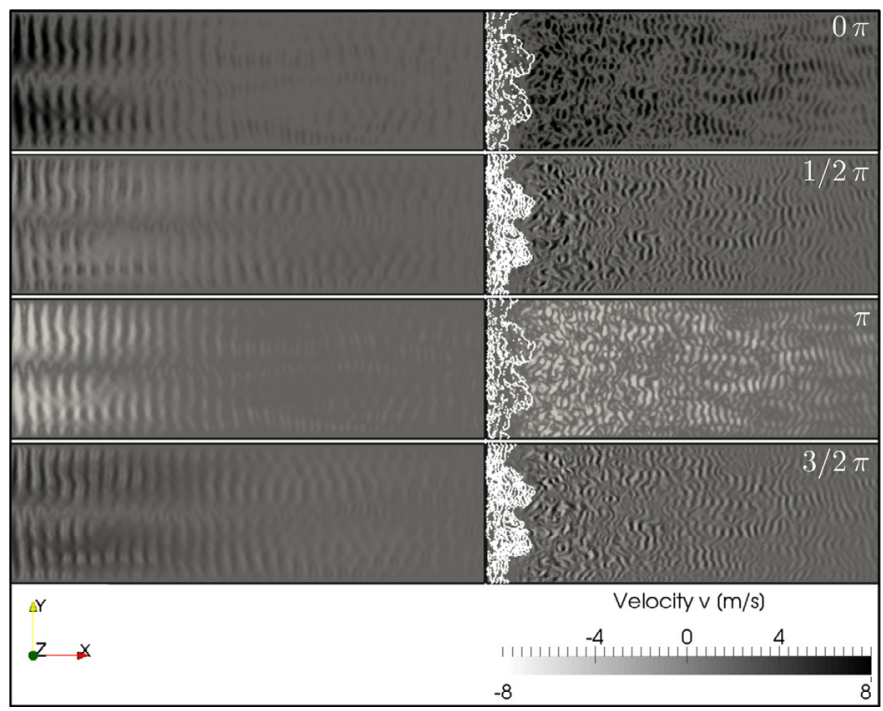

Fig. 22. Velocity fluctuations in $y$-direction during one instability cycle from DMD data with white iso-contours of heat release fluctuations $\left(\dot{Q}=7 \times 10^{6} \mathrm{Wm}^{-3}\right)$. The $x-y$ plane is located at $z=0.079 \mathrm{~m}$ showing the flame holder lip.
Helmholtz solver computes only acoustic pressure activities leading to a random phase in the chamber (Fig. 24, right). However, pressure amplitudes are comparable showing high activity up to the region of the flame holder and low activity downstream.

Note that a different result was obtained by Jourdain and Eriksson [47] for the screech mode. Using a model for the acoustic effects of the screen and adding the effects of equivalence ratio fluctuations, they argue that the screech mode is actually the 6Lx-0Ty-0Tz mode. The present study, based on perfectly-premixed combustion and no screen effects suggests that the $1 L x-2 T y-0 T z$ mode is also a possible candidate. Only new experiments could clarify this issue at this point.

\section{Conclusions}

In the present work an afterburner configuration is investigated with LES. Several regimes observed experimentally (stable operation, longitudinal and transverse self-excited modes) are reproduced using LES with precision. The excitation mechanisms for the modes are identified and flow and flame characteristics discussed. The transverse mode 1 Lx-2Ty-0Tz at $1360 \mathrm{~Hz}$ featured a symmetric flow pattern in longitudinal direction and a mean flame brush deformation associated to the transverse mode in the direction parallel to the flame holder, a feature which had not been reported up to now. The mode shapes predicted by a Helmholtz solver are compared with LES
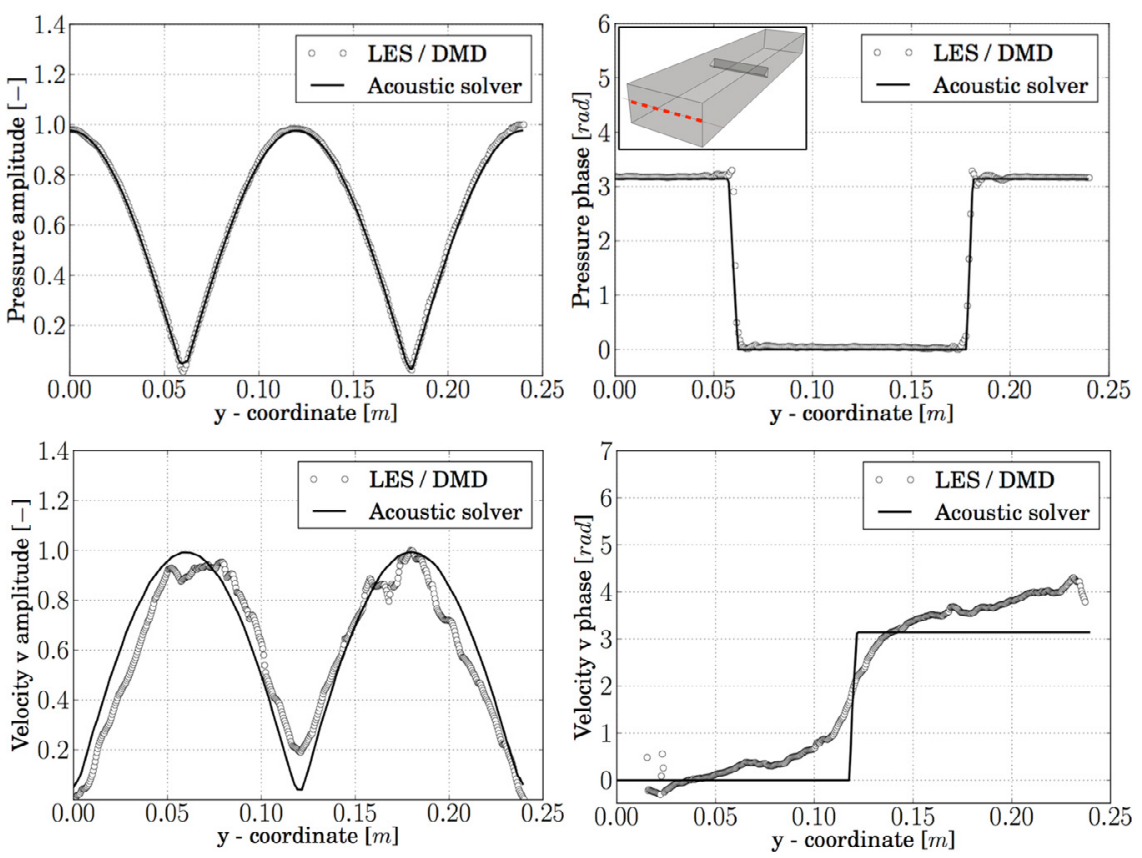

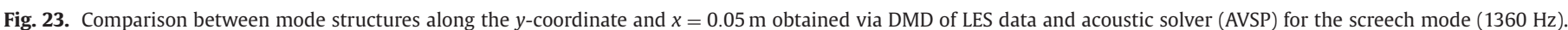
Top: Pressure modulus and phase. Bottom: Velocity $v$ modulus and phase.
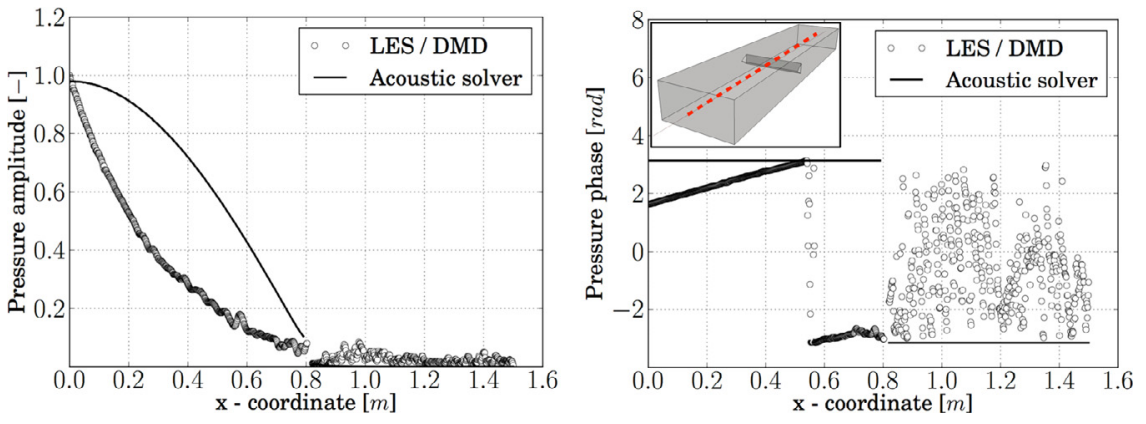

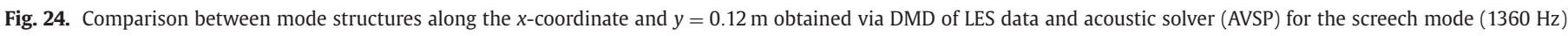
Left: Pressure modulus. Right: Pressure phase. 
data and agree well showing that the present high-order compressible solver is able to capture transverse modes. The results allow to get further insight into instability mechanisms and can help to develop a theoretical framework for transverse modes.

\section{References}

[1] Y. Huang, V. Yang, Prog. Energy Comb. Sci. 35 (4) (2009) 293-364

[2] T. Poinsot, D. Veynante, Theoretical and Numerical Combustion, 3rd ed., 2011 www.cerfacs.fr/elearning.

[3] T.C. Lieuwen, Unsteady Combustor Physics, Cambridge University Press, 2012

[4] M. Fleifil, A.M. Annaswamy, Z.A. Ghoneim, A.F. Ghoniem, Combust. Flame 106 (4) (1996) 487-510

[5] S. Ducruix, D. Durox, S. Candel, Proc. Combust. Inst. 28 (1) (2000) 765-773.

[6] W. Krebs, P. Flohr, B. Prade, S. Hoffmann, Combust. Sci. Tech. 174 (7) (2002) 99128.

[7] K.-U. Schildmacher, R. Koch, S. Wittig, W. Krebs, S. Hoffmann, ASME Turbo Expo 2000: Power for Land, Sea, and Air, American Society of Mechanical Engineers, 2000 V002T02A005; 8 pp.

[8] T. Schuller, D. Durox, P. Palies, S. Candel, Combust. Flame 159 (2012) 1921-1931.

[9] T. Poinsot, S. Candel, Nijhoff, Mathematic Modeling in Combustion and Related Topics, in: NATO ASI Series, vol. 140, Dordrecht, 1987, pp. 185-215.

[10] D.E. Rogers, F.E. Marble, J. Prop. 26 (1956) 456-462.

[11] Y. Mery, S. Ducruix, P. Scouflaire, S. Candel, C. R. Acad. Sci. 337 (6) (2009) 426-437.

[12] B. Emerson, J. O'Connor, M. Juniper, T. Lieuwen, J. Fluid Mech. 706 (2012) 219 250.

[13] Y. Méry, L. Hakim, P. Scouflaire, L. Vingert, S. Ducruix, S. Candel, C. R. Acad. Sci. 341 (1) (2013) 100-109.

[14] F. Baillot, F. Lespinasse, Combust. Flame 161 (5) (2014) 1247-1267.

[15] A. Sjunnesson, S. Olovsson, B. Sjoblom, in: 10th International Symposium on Air Breathing Engines 1991, Nottingham, England, 1991, pp. 385-393.

[16] A. Sjunnesson, P. Henrikson, C. Löfström, CARS measurements and visualization of reacting flows in a bluff body stabilized flame, in: 28th Joint Propulsion Conference and Exhibit, Nashville, TN, 1992, AlAA 92-3650.

[17] A. Sjunnesson, C. Nelsson, E. Max, LDA measurements of velocities and turbulence in a bluff body stabilized flame, in: Fourth International Conference on Lase Anemometry - Advances and Application, ASME, Cleveland, vol. 3, 1991, pp. 8390.
[18] P. Cocks, V. Sankaran, M. Soteriou, 51st AIAA Aerospace Sciences Meeting AIAA 2013-0170, AIAA, 2013, pp. 1-29.

[19] C. Fureby, Proc. Combust. Inst. 28 (1) (2000) 783-791.

[20] E. Giacomazzi, V. Battaglia, C. Bruno, Combust. Flame 138 (4) (2004) 320-335.

[21] R. Erickson, M. Soteriou, Combust. Flame 158 (12) (2011) 2441-2457.

[22] G. Jourdain, L.-E. Eriksson, 18th AIAA/CEAS Aeroacoustic Conference 2012, 2012 2147, AIAA, 2012, pp. 1-11.

[23] G. Jourdain, L.-E. Eriksson, in: ASME Turbo Expo 2010: Power for Land, Sea, and Air, American Society of Mechanical Engineers, 2010, pp. 269-278.

[24] F.E.C. Culick, AGARD Conference Proceedings, AGARD, vol. 450, 1988, pp. 1-74.

[25] J.-F. Parmentier, P. Salas, P. Wolf, G. Staffelbach, F. Nicoud, T. Poinsot, Combust. Flame 159 (7) (2012) 2374-2387.

[26] Y. Huang, H.G. Sung, S.Y. Hsieh, V. Yang, J. Prop. Power 19 (5) (2003) 782-794.

[27] C. Duwig, C. Fureby, Combust. Flame 151 (1-2) (2007) 85-103.

[28] P. Schmitt, T. Poinsot, B. Schuermans, K.P. Geigle, J. Fluid Mech. 570 (2007) 17-46.

[29] G. Staffelbach, L. Gicquel, G. Boudier, T. Poinsot, Proc. Combust. Inst. 32 (2) (2009) 2909-2916.

[30] P. Wolf, R. Balakrishnan, G. Staffelbach, L. Gicquel, T. Poinsot, Flow Turbul. Combust. 88 (2012) 191-206

[31] F. Nicoud, L. Benoit, C. Sensiau, T. Poinsot, AIAA J. 45 (2007) 426-441.

[32] O. Colin, F. Ducros, D. Veynante, T. Poinsot, Phys. Fluids 12 (7) (2000) 1843-1863.

[33] T. Schönfeld, M. Rudgyard, AIAA J. 37 (11) (1999) 1378-1385.

[34] F. Nicoud, H. Baya Toda, O. Cabrit, S. Bose, J. Lee, Phys. Fluids 23 (2011) 85-106.

[35] O. Colin, Simulations Aux Grandes Échelles de la Combustion Turbulente Prémélangée dans les Statoréacteurs (Ph.D. thesis), INP Toulouse, 2000.

[36] A. Sengissen, J.F.V. Kampen, R. Huls, G. Stoffels, J.B.W. Kok, T. Poinsot, Combust. Flame 150 (2007) 40-53.

[37] F. Charlette, C. Meneveau, D. Veynante, Combust. Flame 131 (1) (2002) 159-180.

[38] T. Poinsot, S. Lele, J. Comput. Phys. 101 (1) (1992) 104-129.

[39] V. Granet, O. Vermorel, T. Leonard, L. Gicquel, T. Poinsot, AIAA J. 48 (10) (2010) $2348-2364$.

[40] N. Guezennec, T. Poinsot, AIAA J. 47 (2009) 1709-1722.

[41] S.B. Pope, Turbulent Flows, Cambridge University Press, 2000.

[42] N. Peters, Turbulent Combustion, Cambridge University Press, 2001.

[43] K.K. Kuo, Principles of Combustion, John Wiley, New York, 1986.

[44] L. Rayleigh, Proc. London Math. Soc 4 (1878) S1-10.

[45] P.J. Schmid, J. Fluid Mech. 656 (2010) 5-28.

[46] P. Palies, D. Durox, T. Schuller, S. Candel, J. Fluid Mech. 672 (2011).

[47] G. Jourdain, L.-E. Eriksson, 16th AIAA/CEAS Aeroacoustics Conference (31st AIAA Aeroacoustics Conference) 2010, AIAA, 2010, pp. 1-16. 